\title{
Evaluation study for administrative work of Saudi Universities Sport Federation based on Total Quality Elements
}

\author{
Dr. Ahmed Mansour Alsentali* \\ Dr. Ahmed Fathy Ali**
}

\begin{abstract}
:
This research aims to examine the current administrative system of Saudi Universities Sport Federation (SUSF) based on quality assurance. Researchers used descriptive method - case study - due to its appropriateness for the nature of the present research. Researchers collected data through The Current Administrative System Questionnaire (CASQ) for SUSF employees. The Survey of Total Quality Assurance for SUSF top management (STQA-Management) and The Survey of Total Quality Assurance for SUSF beneficiaries (STQA-Beneficiaries). Results show that SUSF's goals are clearly set, also SUSFs' plans are consistent with the general goals of the Sports Welfare Movement at Saudi Arabia. However, beneficiaries reported some limitation in implementing the principles of total quality assurance management. Therefore, researchers suggested an administrative system for SUSF based on total quality assurance.
\end{abstract}

\section{Introduction and Statement of the Problem:}

Modern management is currently seeking to develop and upgrade its techniques in order to keep up with administrative change and development at the global level $(9: 15)$.

The institutions which believe that the function of management is to organize resources and employ them within the institutions to achieve external results will not be able to hold out in a world dominated by constant competitiveness, change and modern technology $(2: 14)$.

Therefore, it is necessary to pay serious attention to the management techniques through which these institutions are run and managed in order to achieve competitive advantage. Quality is considered one of those elements through which competitive advantage, which is strategically necessary for the continuity and success of organizations, can be achieved $(36: 8)$.

Concern with the quality of services provided by governmental organizations has been recently increased due to the problems impeding the performance of these organizations. Therefore, several organizations have adopted certain management techniques which proved to be effective in achieving improvement, and of these techniques is total quality management $(2: 257)$.

Total quality management is considered one of the modern management trends adopted for the purpose of attaining better performance that helps solve several problems and difficulties related to quality, performance improvement and competitiveness of the organization $(3: 6)$.

The higher education sector is one of the most important sectors in the field of youth work as it involves an elite of the youths of the Kingdom of Saudi Arabia. They are categories that sports services must be directed to them as being one of human preparation elements and his physical, mental, psychological and social rehabilitation in a consistent way with the society philosophy in which he lives in order to ensure him the ability of global competitiveness $(5: 2)$.

Youths at the higher education stage represent the creative power of the political, economic and social future of the society. Therefore, they should be prepared for useful citizenship through practicing several varied activities that contribute to developing their potentials and abilities

\footnotetext{
* Associate professor, Northern Borders University, Arar, KSA.

** Associate professor, Faculty of Physical Education, Assiut University, ARE. Northern Borders University, Arar, KSA.
} 
particularly the sports activities (11:241). The Saudi Universities Sports Federation (SUSF) is the main pivot for the provision of the suitable atmosphere for sports practice in order to develop students at the sports level through action plans, internal and external discussions, particularly external ones, to strengthen ties between Saudi Arabia and Arab and foreign countries, provide contact among university youths and help Saudi Arab participate in international forums to elevate the university sports level. Thus, all organizations concerned with sports and education in the kingdom should cooperate to provide all the resources necessary for serving the youths of the kingdom (1).

In addition, contests and championships between member bodies and institutions should be organized with the aim of expanding their sports activities, and elevating their technical and administrative efficiency. The federation provides technical assistance and guidance to its members in order to elevate their sport leadership levels through growing human development programs and the encouragement of voluntary work within the university sports circle.

This importance imposes the necessity of caring for the SUSF as one of the most important bodies through which sports activity is run and managed at the universities in order to make it of high quality as a sports service product through improving its operations, maximizing its output in a way that achieves beneficiaries' satisfaction, increases their interest in it and achieves the end of practicing it.

Thus, it is clear that the SUSF has an important role in spreading the culture of sports practice among student communities, and expanding the base of students practicing sports activity at Saudi universities. This can largely contribute to the integrated preparation of a graduate. Sports activity is an educational means that helps prepare the good citizen who is able to bear responsibility towards the society in which he lives and achieve its development and progress.

Through the researchers' administrative work as one of them is vice dean for student' affairs at Northern Borders University which is in charge of the supervision of sports activity, and a sports activity adviser at the SUSF, and the second is a supervisor at the Student Sports Activity Administration at Northern Borders University, and through their interaction and contact with the activities, championships and events organized by the SUSF since its establishment in $1431 \mathrm{H}$. till now, they believe that the significance of the present study is evident in its practical aspect through providing a scientific image of the managerial reality at the SUSF in the light of the essential elements of this developed management technique. In addition, it is possible for the federation to benefit from the findings of the present study through reaching a suggested conceptualization for total Quality that will increase the effectiveness of the federation in achieving its objectives.

\section{Research Objectives:}

The present research aims at studying the managerial reality at the SUSF in the light of the essential elements of total quality. This can be achieved through answering the following questions:

1. What is The Current Administrative System at SUSF?

2. What are the Total Quality Assurance for SUSF?

3. What is the suggested conceptualization for administrative work at the SUSF in the light of the essential elements of total quality?

\section{Methodology: \\ Research Method:}

The researchers used the descriptive method (case study) due to its appropriateness for the nature of the present research.

\section{Research Sample and Population:}

The research population consists of 12 SUSF members of the board of directors, 14 SUSF advisers, and 152 beneficiaries including member public and private universities and colleges. The research sample involved two members of the board of directors, 8 federation advisers and 106 beneficiaries including member public and private universities and colleges.

\section{Data Collecti on Tools:}

The researchers designed three questionnaire forms distributed as follows: 


\section{The Current Administrative System Questionnaire (CASQ) for SUSF employees:}

The researchers have identified the first questionnaire axes through examining some similar studies (3), (6), (9), (10), (12), (13), (16), (17), (17), (19), and (20). A group of 8 specialized experts in the field of general management and sports management evaluated the first questionnaire and determined the appropriateness of its axes from 1 December 2015 till 7 December 2015. The findings were that the axes of the objectives, planning, resources and control got $100 \%$ of the experts' views. Meanwhile the axes of leadership and organization got $87.5 \%$ of their views. In addition, the axes of communication, financing and activity programs are eliminated as they got less than $75 \%$ ( the minimum percentage which the researcher have set to approve of the axes) of the experts' views.

The questionnaire statements were then formulated in the light of the concluded axes based on the experts' views in their preliminary formula. They contained 182 statements divided into 6 axes. They were then referred to the experts from 21 December 2015 till 30 December 2015.

The findings have led to eliminating the less $75 \%$ approved statements, namely $(15,17,23$, 26 and 29) from the axes of objectives. Whereas statements $(5,10,18,28$ and 33) were eliminated from the planning axis, statements $(5,14$ and 22$)$ were eliminated from the organization axis. In addition, statements $(6,10$ and 15$)$ were eliminated from the leadership axis, while statements $(12,18$ and 20) and statements (7 and 18) were eliminated from the control axis. Therefore, the questionnaire contained 161 statements after reviewing the experts' views and eliminating 161 statements which were less than $75 \%$. The approved statements formed the final construction of the questionnaire related to the reality at the SUSF.

\section{Statistical Coefficients:}

The questionnaire was administered to 20 subjects of the research population and outside the main research sample during the period from 10 January, 2016 to 20 January, 2016 in order to calculate the statistical coefficients of the questionnaire form.

\section{Reliability and Validity:}

The researchers verified the internal validity of the questionnaire statements as the correlation coefficient was calculated between the score of each statement and the axis total score to which it belongs. It is significant at $\mathrm{P} 0.05$ as it ranged between 0.54 and $0.95>$ the $\mathrm{R}$ value $(0.444)$. It was also calculated between the axes and the questionnaire form total score. It was significant at P 0.05 as it ranged between 0.83 and $0.97>$ the $\mathrm{R}$ value (0.444).

To calculate the reliability of the questionnaire form, the researchers used the semi-partial method of the questionnaire statements. The correlation coefficient was calculated for the odd and even statements of each of the questionnaire form axes and between the odd and even statements of the form as a whole. It was significant at the P 0.05 as it ranged between 0.94 and 0.99 . Thus, the final construction of the questionnaire form was realized (Appendix 1). It contained six axes with 161 statements and the triple scoring scale was used.

\section{Questionnaire Form of Total Quality Assurance for SUSF top management (STQA- Management) \& The Survey of Total Quality Assurance for SUSF beneficiaries (STQA- Beneficiaries):}

The researchers determined the axes of the second and third questionnaires through reviewing the relevant specialized scientific references (2), (3), (4), (9), (13), (16), (18), (21), (22), (23), and (25). They were referred to the experts to evaluate the appropriateness of these axes from 1 December 2015 till 7 December 2015. The experts approved the proposed axes as the percentage of their approval ranged between $62.5 \%$ and $100 \%$. The researchers agreed to consider the ratio of $75 \%$ as the minimum percentage to approve those axes. Thus, seven axes were approved, namely top management, customer satisfaction, human resources management, information system, education and training, staff participation, and continuous improvement. Four axes were excluded, namely organizational culture, quality level, communication system, standards).

The 125 statements of the second questionnaire (Essential Elements of Total Quality for the SUSF Top Management) were then preliminary formulated. The 102 preliminary statements of the third questionnaire (Essential Elements of Total Quality for Beneficiaries of the SUSF services) were formulated. They were then referred to the experts from from 21 December 2015 till 30 December 2015. The findings have led to exclusion the statements which got an approval percentage of less than 
$75 \%$, namely (4,7 and 10), from the customers' satisfaction axis, (6 and 12) from the human resources management axes and (3.10 and 11) from the education and training axis, whereas statements ( 1 and 5) were excluded from the staff participation axis, statements $(4,7$ and 9) were excluded from the information system axis. In addition, statements (12, 17 and 19) were excluded from the continuous improvement axis. Therefore, the questionnaire contained 109 statements after reviewing the experts' views while excluding statements which got an approval percentage of less than $75 \%$. These statements formed the final form of the Essential Elements of Total Quality for the SUSF Top Management Questionnaire.

As for the form of the Questionnaire of the Essential Elements of Total Quality for Beneficiaries of the SUSF services, the second form findings have led to the exclusion of the statements which got an approval percentage of less than $75 \%$, namely (4 and 14) from the top management axis, (7 and 12) from the human resources management axis, $(3,8$, and 11) from the information system axis and (10) from the continuous improvement axis. Thus, the 94 statements constitute the final form of the Questionnaire of the Essential Elements of Total Quality for Beneficiaries of the SUSF services, after considering the experts' views and excluding the statements which got an approval percentage of less than $75 \%$.

\section{Statistical Coefficients:}

The statistical coefficients were calculated during the period from 10 January, 2016 to 20 January, 2016 to verify validity and reliability of the two questionnaire forms.

\section{First: Questionnaire Form of Total Quality Assurance for SUSF top management (STQA- Management).}

\section{Validity and Reliability:}

The researchers used content validity in order to verify the statements of the questionnaire form. The percentage of their appropriateness and formulation was calculated through presenting the questionnaire form to a group of experts to rate and judge its items quantitatively and qualitatively. The content validity of the form components was established and they were proved to be highly statistically significant.

Due to the limited number of the population of SUSF's members of the board of directors and advisers, there was no sample to standardize the form. Thus, a similar sample was used to pilot the form comprising 5 members of the board of directors of the Saudi Handball federation to standardize the form. The Cronbach's Alpha was calculated for the first and second applications of each of the form axes and the form as a whole. Cronbach's Alpha was significant at P $0.05>$ its table value at $\mathrm{p}$ 0.85 as it ranged between $(0.70)$ and (0.98). Thus, the final questionnaire form was constructed containing seven axes and 109 statements with a 3-point scale.

\section{Second- Questionnaire Form of Total Quality Assurance for SUSF beneficiaries (STQA- Beneficiaries): \\ Validity and Reliability:}

To establish the validity of the questionnaire, the researchers the verified the internal consistency of the questionnaire statements as they calculated the correlation coefficient between the score of each statement and the total score of the axis to which it belongs. It is significant at $P=0.05$ as it ranged between 0.65 and 0.95 , as it was greater than tabular $\mathrm{R}$ value $(0.444)$. The researchers also calculated the correlation coefficient between the axes and the total score of the questionnaire form. It was significant at $P=0.05$ as it ranged between 0.68 and 0.91 , as it was greater than tabular $\mathrm{R}$ value (0.444).

To calculate the reliability of the questionnaire form, the researchers used the split-half method to calculate the reliability of the questionnaire statements. The correlation coefficient was calculated for the odd and even statements of each of the axes the questionnaire form and between the odd and even statements of the form as a whole. It was significant at the $P=0.05$ as it ranged between 0.88 and 0.98 , as it was greater than tabular $\mathrm{R}$ value $(0.444)$. Thus, the final format of the questionnaire form was constructed (Appendix 3). It contained seven axes with 94 statements and the 3-point scale was used. 


\section{Application of the Form to the Research Main Sample:}

After establishing the validity and reliability of the questionnaire forms, the researchers have administered them to the main research sample during the period from 20 February, 2016 to 20 March, 2016. The managerial reality form was administered to 106 of the beneficiaries of the SUSF offered services including the officials of activities at public and private universities and faculties participating in the SUSF championships. The Questionnaire Form of the Essential Elements of Total Quality for Top Management was administered to 10 members of the SUSF's board of directors and advisers.

A number of 91 forms of the Questionnaire of the Essential Elements of Total Quality for Beneficiaries of the SUSF's services was administered to activities officials at the state-run and private universities and faculties participating in the SUSF tournaments. After checking all the collected forms, 83 forms were eliminated as the participants lacked seriousness and the researchers could not get back 8 other forms.

\section{Analysis and Discussion:}

Based on the statistical manipulations of the research data, findings will be displayed in the light of verifying the research objective and answering the research questions:

\section{First question: What is current administrative system of the SUSF?}

- The percentage of the first axis (objectives) ranged between (58.5\% and 58.7\%) as statements (3), and (4) got the highest percentage and ranged between $(85.7 \%$ and $82.6 \%)$. This confirms that the frame of reference for the federation's goals comes in line with the State's public policy. This policy focuses on the paramount importance of paying attention to the youths and making available all suitable opportunities to exploit their abilities positively. The federation's goals are consistent with the general objectives of the sports movement sponsorship at the Saudi universities.

- The percentage of the second axis (planning) ranged between (49.1\% and 84.9\%) as statements (2), (22), and (23) got the highest percentage (84.9\%). This means that the side related to devising the federation activity plan comes in the same educational context of the Saudi university sports objectives and in line with the set of rules and regulations organizing work at the federation in order to contribute to achieve its cherished goals through the international, regional and gulf university participation.

- The percentage of the third axis (organization) ranged between $(45.7 \%$ and 80.4$)$ as the statements (1), (8), and (9) obtain a high percentage of (80.4). This affirms the existence of a clear organizational structure of the SUSF which is accredited by the ministry of higher education. In addition, the federation observes the scientific bases in terms of the organizational structure appropriate for the nature of work management at the federation. It also clearly determines the tasks and specializations of all positions and selects the top management systems in line of subjective standards.

- The percentage of the fourth axis (leadership) ranged between (45\% and 82.6) as the statements (8), and (17) obtain a high percentage of (82.6). This indicates that the leadership pattern of some university activities officials hinders the realization of some federation's goals and the increased number of the participants affiliated to those universities. The rewards and incentives, given to the participants who occupy front activity positions by the federation, lead to support their moral spirit and stimulate others to exert further efforts in the tournaments in order to achieve results that in their turns let them obtain these rewards and incentives.

- The percentage of the fifth axis (potentials) ranged between (53.2\% and 84.2) as the statements (4), (9), (20) and (21) obtain high percentages ranging between (77\% and 84.2\%). This confirms that the federation stipulates requirements that force the universities participating in the sports activities to provide legally accepted courts for all the activities in which they participate. This encourages the universities whether to provide the budgets necessary for establishing these courts or form real partnerships with the nearest clubs till they accomplish their own courts. As such they can hold their official matches affiliated to the SUSF league in such courts. Encouraging the participants in the federation activities at the end of every sports season, the federation holds a celebration to honor the distinguished universities. This has a psychological positive impact on 
the participants. The federation attempts to direct its potentials to serve the beneficiaries through providing all the potentials, and means of modern technology to conduct and expedite work performance.

- The percentage of the sixth axis (control) ranged between (52.5\% and 79.6) as the statements (2), (3), (9) and (11) obtain high percentages ranging between (79.6\% and 75.5\%). This indicates that the federation annually evaluates universities in order to determine their actual levels in the light of their achieved results. It designates its advisers to follow up activities in each university of the universities and faculties. This contributes to sustain communication and remove obstacles. The administrative and financial department in each university follows up the activity spending aspects in order to help redirecting them to the right path. Meanwhile the student' affairs deanship at each university follows up the activities to implement the federation plans and eliminate all obstacles facing them.

Table 1 Estimated score, percentage of the research sample responses to the axes of current administrative system of the SUSF $(N=106)$

\begin{tabular}{|c|c|c|c|c|}
\hline Serial No. & Axis & $\begin{array}{c}\text { Estimated } \\
\text { score }\end{array}$ & Percentage & Order \\
\hline 1 & Objectives & 9849 & 71.47 & Second \\
\hline 2 & Planning & 12670 & 72.44 & First \\
\hline 3 & Organization & 8026 & 68.83 & Fourth \\
\hline 4 & Leadership & 8764 & 68.90 & Third \\
\hline 5 & Resources & 12522 & 65.63 & Sixth \\
\hline 6 & Control & 6984 & 65.89 & Fifth \\
\hline
\end{tabular}

Table 1 indicates the following:

The planning axis came first through the sample responses by (72.44\%). This affirms the findings of Mona Abdel Monem's study (2005) where she referred to the planning significance in the optimal use of all available potentials and resources to achieve the objectives (18:16).

The objectives axis came second by (71.47\%). This refers to the SUSF objectives clarity and proves that the staff and federation related vision is clear. This is considered as one of the administrative work success which determines the necessary procedures and potentials to realize the objectives. It provides suitable measuring instruments to verify the extent of objectives realization. This result conforms that of Hassan El-Shafae (2003) in the sense that there is a necessity to inform the staff of the objectives, policies, plans, programs, procedures and the changing developments and circumstances (8:221). It is also compatible with the findings of both Mamdouh Mahmoud Othman's study (2007) of work management and implementation (17:84) and Langan, Patrick, William' study (1989) (24) which concluded that unclear objectives and lack of objectives negatively affect the improvement and development of work.

The leadership axis comes third by (68.90). This is because leadership is one of the most effectual processes on the behavior as it affects the individuals' motivation and their work satisfaction $(7: 124)$. This is compatible with that of Mamdouh Mahmoud Othman's study (2007) which asserts that the adopted leadership is suitable to a certain extent for work management and implementation, but it is not much correlated with the achievement of improvement, development and creative thought at work.

Meanwhile the organization axis comes fourth by $(68.83 \%)$. The researchers believe that this a low percentage as the organization factor is one of the most important actors of the management process related to determining and ordering relations between units, departments, sections and tasks of the organizations. This conforms the findings of Mohamed Gamal Mohamed Ali who refers to unifying and gathering efforts in one outcome towards the objective through determining, identifying and dividing responsibilities into certain categories and determining the organizational relations as well (6:30).

The control axis came fifth by $(65.89 \%)$. The researchers believe that it is a low percentage as control is one of the management factors that has the great effect in verifying what has been realized 
of the objectives in line with the devised plans. This is an evident on the weak control role of the SUSF.

The potential axis came in the last rank by $(65.63 \%)$. The researchers believe that this percentage is illogical as the SUSF is an outcome of mutual cooperation between the ministry of higher education, universities, state-run and private faculties which enjoy the highest concern of the state and have increasingly financial support year after another accompanied with providing the highest potential in most of the universities. The researcher believe that the problem does not dwell on providing potentials but rather in the management system which manages these potentials to achieve the optimal return and best exploitation. Thus, the researchers have answered the first question: What is The Current Administrative System at SUSF?

\section{The second question: What are the Total Quality Assurance for SUSF?}

- The percentage of the first axis (top management) ranged between (64\% and 100\%) as statements (22 and 24) got the highest percentage (100\%). This indicates that top management believes in the importance of activity supervisors' participation and student activity coordinators in the planning process.

- The percentage of the second axis (customers' satisfaction) ranged between (60\% and 84\%) as statements (2 and 3) got the highest percentage (84\%). This indicates the federation's support for university sports activity and its treatment of the staff as being not only the federation activity executives but the main partners. The federation constantly modifies its services and programs according to the beneficiaries' needs (member public and private universities and colleges). This leads to the development of the services provided by the federation a year after another.

- The percentage of the third axis (human resources management) ranged between (64\% and 100\%) as statement (1) got the highest percentage (100\%). This indicates the top management belief of the importance of having a complaint unit in order to expedite providing solutions to the problems facing them. It also believes in the importance of beginning the activation of its role.

- The percentage of the fourth axis (education and training) ranged between (68\% and 92\%) as statement (1) got the highest percentage (92\%). This asserts that the top management is keen on conducting training and educational programs for the federation individual staff to improve their experience level, ability and knowledge.

- The percentage of the fifth axis (staff participation) ranged between (64\% and 96\%) as statement (1) got the highest percentage (96\%). This indicates the top management's conviction of the necessity of the federation's staff participation in handling the problems facing the federation due to the close contact with those problems and knowledge of their identity. Therefore, they are the best to propose solutions for such problems.

- The percentage of the sixth axis (information system) ranged between (64\% and 96\%) as statements ( 2 and4) got the highest percentage (96\%). This indicates the necessity of confidential communication between top management and all affiliates of the federation to inform them of their personal improvement levels and their defects as well in order not to be upset. In addition, the human aspects should be observed as well, which will be positively reflected on their performance. The information analysis within the federation should be positively conducted in the form of using data and statistically analyzing them to provide accurate and reliable data for the process of decision making.

- The percentage of the seventh axis (continuous improvement) ranged between (52\% and 88\%) as statement (13) got the highest percentage (88\%). This asserts that the federation officials carry out several tasks such as collection of statistical data, their analysis to conclude their findings and their documentation. 
Table 2 Estimated score, percentage of the research sample responses for Total Quality Assurance for SUSF top management (STQA-Management) (N=10)

\begin{tabular}{|c|c|c|c|c|}
\hline Serial No. & Axis & Estimated score & Percentage & Order \\
\hline 1 & Top management & 79.26 & 1506 & Fifth \\
\hline 2 & Customers' satisfaction & 72.89 & 328 & Sixth \\
\hline 3 & $\begin{array}{c}\text { Human resources } \\
\text { management }\end{array}$ & 80 & 520 & Third \\
\hline 5 & Education and training & 81.2 & 406 & First \\
\hline 6 & Staff participation & 80 & 400 & Third \\
\hline 7 & Information system & 80.4 & 402 & Second \\
\hline
\end{tabular}

Table (2) indicates the following:

The axis of education and training came first through the research sample responses by (81.2\%), followed by the information system axis (80.4\%), then came both the staff participation axis and human resources management axis (80\%). They are followed by the axis of customers' satisfaction $(72.9 \%)$ and the continuous improvement axis came at the last rank (72.42\%).

The findings of this questionnaire indicate that the top management has a reasonable level of realizing the essential elements of total quality, but there are several obstacles that impede the optimal implementation of the Total Quality management system. The most important of these obstacles are the lack of human resources necessary for development and the necessary full convention of the top management of the importance of this management system to develop the individuals' skills necessary for its implementation. This entails organizing educational and training courses related to Total Quality that help elevate and develop the individuals' levels, abilities. This is compatible with the findings of Mona Abdel Moneam (2005) which asserted the weak implementation of Total Quality management due to the need of such a system of high ability and skills level for the instruments and potentials.

As for the answer of the research question on The Survey of Total Quality Assurance for SUSF beneficiaries (STQA-Beneficiaries) $(\mathrm{N}=70)$ :

of The percentage of the first axis (top management) ranged between $(20 \%$ and $89.7 \%$ ) as statement (18) got the highest percentage (89.7\%). This indicates that top management is keen, in its directions, on preventing the occurrence of mistakes instead of correcting them after their occurrence and then looking for the reason behind them. This may either lead to avoiding the occurrence of mistakes or correcting them on the spot instead of waiting for another mistake to occur.

- The percentage of the second axis (customer satisfaction) ranged between (31.4\% and $84.6 \%$ ) as statements $(5,6,7,8$ and 9$)$ got the highest percentage ranging between (31.4\% and $84.6 \%)$. This indicates that there are several and various means of communication between the beneficiaries and the federation as they electronically communicate with the federation. They can also communicate by post, by phone or sometimes personally when necessary. The beneficiaries are warmly hosted and welcomed whenever they are at the federation.

- The percentage of the third axis (human resources management) ranged between $(63.4 \%$ and $78.3 \%$ ) as statement (2) got the highest percentage (78.3\%). This indicates that the federation has highly skilled, efficient and quick statistics and data entry staff. This is evident in data upgrading and regular entry of the results of the contests in the federation's website. In addition, the federation's publications record all the activities and contests held by the federation which include detailed data on all the federation's activities in every sports season.

- The percentage of the fourth axis (education and training) ranged between (50.9\% and $73.7 \%$ ) as statements (10 and 12) got the highest percentage (73.7\%). This indicates that in spite of the training courses and programs which the staff receive to help achieve the optimal exploitation of work time, the content of the administrative development programs which they receive need to be 
developed according to modern management techniques, so that they can keep up with the latest developments worldwide.

- The percentage of the fifth axis (staff participation) ranged between (57.7\% and $82.9 \%$ ) as statement (3) got the highest percentage (82.9\%). This indicates that the federation's concept of quality means observation of the provision of services to the customers quickly and with as few mistakes as possible. Use of modern technology should also be observed in the communication between the federation and other bodies. Meanwhile, the federation policies lack some quality components such as considering the beneficiary as the source of though, and inspiration to fulfill the task and the beneficiaries' participation in devising the federation's goals and listening to their development proposals.

- The percentage of the sixth axis (information system) ranged between $(78.3 \%$ and $61.1 \%$ ) as statements (6 and 7) got the highest percentage ranging between $(77.1 \%$ and $78.3 \%)$. This indicates the clarity of instructions issued by the federation and their easy implementation. This also asserts that the beneficiaries' responses distinguished all the federation management related to the activities records which are electronically conducted via the computer.

- The percentage of the seventh axis (continuous improvement) ranged between (78.9\% and 57.9\%) as statement (4) got the highest percentage (78.9\%). This indicates the federation's continuous attempts to develop its services and activities according to the beneficiaries' desires.

Table 3 Estimated score, percentage of the research sample's responses to the axes of The Survey of Total Quality Assurance for SUSF beneficiaries (STQA-Beneficiaries) $(\mathbf{N}=\mathbf{7 0})$

\begin{tabular}{|c|c|c|c|c|}
\hline Serial No. & Axis & $\begin{array}{c}\text { Estimated } \\
\text { Score }\end{array}$ & Percentage & Order \\
\hline 1 & Top management & 3886 & 61.68 & Seventh \\
\hline 2 & $\begin{array}{c}\text { Customers' } \\
\text { satisfaction }\end{array}$ & 4546 & 68.36 & Fifth \\
\hline 3 & $\begin{array}{c}\text { Human resources } \\
\text { management }\end{array}$ & 2456 & 70.17 & Second \\
\hline 4 & $\begin{array}{c}\text { Education and } \\
\text { training }\end{array}$ & 3280 & 66.94 & Sixth \\
\hline 5 & Staff participation & 3470 & 70.82 & First \\
\hline 6 & Information system & 1960 & 70.00 & Third \\
\hline 7 & $\begin{array}{c}\text { Continuous } \\
\text { improvement }\end{array}$ & 2650 & 68.83 & Fourth \\
\hline
\end{tabular}

Table (3) indicates the following:

The staff participation axis came first through the sample responses by (70.82\%), followed by the human resources management axis $(70.17 \%)$. Then came the customers' satisfaction axis $(68.36 \%)$. They are followed by the education and training axis $(66.94 \%)$ and the top management axis came at the last rank (61.68\%).

The questionnaire findings refer to there is a need to reinforce the culture, system and fundamentals of Total Quality among those in charge of the federation management work. The lack of implementing the axes of top management Total Quality management, customers' satisfaction, education and training, continuous improvement does somehow not achieve the satisfaction of beneficiaries of federation offered services and it does not satisfy their needs. This is evident through lack of giving them the opportunity to devise the federation's goals and the non-existence of a complaint unit to receive their complaints. In addition, it is evident as well the lack of educational and training programs which help develop their abilities. The beneficiaries of federation provided services lack holding meetings even monthly ones to hear their complaints or proposals to improve the work performance quality.

Therefore, the researchers have answered the second questions: What are the Total Quality Assurance for SUSF?

The third question: What is the suggested conceptualization for administrative work at the SUSF in the light of the essential elements of total quality? 
This concept is proposed in the light of main principles and conceptions of the Total Quality management. Based on the present study findings of diagnosing the real administrative situation and through assessing the current situation of the fundamental facets of the SUSF Total Quality management, the suggested conceptualization consists of the following implementation objectives and procedures:

\section{- The suggested conceptualization philosophy}

1. The occurrence of change related to improvement requires reconstruction of the social system. It is the management responsibility, so as it is consistent with the organization vision and value, organization power forms, communication patterns and interaction among its individuals. The organization social construction is one of the most important factors contributing to achieve the team work, motivation, innovation, risk and taking responsibility.

2. The top management convention and belief of the SUSF Total Quality system implementation as being the first responsible body for implementing this system which is the basis of success and excellence.

3. Developing the internal federation work atmosphere to achieve the internal and external beneficiaries' satisfaction and hence generally realize the federation cherished objectives.

4. Handling the defect aspects, overcoming difficulties and devising solutions for these problems should be carried out in the light of studying and investigating the actual circumstances, existing problems and studying the available potentials and abilities.

5. Avoiding the change resistance on the part of some staff through developing their realization and awareness of the Total Quality management concept; its significance, benefits, advantages resulting from its successful implementation and how this pattern can be changed.

6. Taking into considerations some concepts like team work, improvement of communication, preparing an integrated information system, gaining the customers' satisfaction, observing the importance of education, training and continuous improvement while engaging them in the decision making process and other Total Quality concepts and attempting to realize them.

7. Abandoning the traditional management methods while adopting the modern techniques in consistency with the Total Quality principles.

- The suggested conceptualization philosophy focuses on some important points. They are as follows:

1. The administrative procedures should be modified and the emerged defect, default and lapses should start to be improved. It is necessary to solidify the Total Quality fundaments as an intellectual framework that deals the developed and changing reality.

2. Measuring standards should be devised to measure the management work quality at the federation where such standards will function as a guide and conductor during the implementation.

3. The responsibility of quality realization should not be restricted to the top management only but all the federation staff should take part including the board of directors, advisers, administrators and the student activity coordinators at the universities.

4. The quality continuous improvement should be an essential of the federation culture. All the federation staff should be provided with instruments necessary for continuous improvement of the services they offer.

- Mechanisms of the suggested conceptualization implementation

First- Preparation Stage:

This stage attempts to prepare the suitable atmosphere for accepting the modernization ideas at the federation, spread the Total Quality culture, determine the possibility of implementing this culture, work out the federation's goals in consistency with the quality standards and discuss the difficulties that they expect to face. This stage includes the following:

\section{A. Obtain the support of Top Management:}

The implementation of Total Quality system entails the top management's belief, understanding and realization of this system. The top management role in implementing this system can be summarized as follows:

1. Dissemination of Total Quality culture.

2. Assessing the need for Total Quality Management. 
3. Adherence to Total Quality.

\section{B. Quality Management:}

Quality management can be created within the federation to assume full responsibility of Total Quality management implementation. Its members range from 10-15 members as they represent all the management levels in order to vary skills and expertise while constantly communicate with the beneficiaries of the federation offered services. It works as well towards achieving necessary changes for this system implementation. Subsequently, an organizational structure of the Total Quality management can be formed that clarifies all authorities, specializations and responsibilities of all management positions and the federation related committees.

\section{Setting the Federation's Objectives and Quality Policy:}

The quality management devises a set of objectives that expands the practice base, spreads the sports culture. It should be observed that those objectives should vary between long-term and short-term ones. Objectives should be related to the customers' (i.e. beneficiaries) satisfaction, their needs and requirements, and competition under the modern developments at domestic, regional and international levels.

\section{Second- Planning Stage:}

A. Identify coordinator of $t$ he Total Quality management:

A Total Quality management coordinator is appointed to function as link between the quality management and the federation committees. He should be selected in the light of subjective standards that reflect the characteristics and skills of a distinguished character. He should be fully aware of the essential elements of total quality as a management system and should have innovation ability, creativity, and effective communication with others.

\section{B. Training of the Quality Management Members:}

The quality management members and coordinator should be trained on the concepts, principles and instruments of Total Quality to help them introduce what is new in the field of quality.

\section{Developing the Implementation Plan:}

This stage aims to develop implementation plan of Total Quality Management based on the objectives determined at the preparation stage. It includes support and sustain of the top management to establish quality management and devise the policies necessary for implementation.

\section{Third- Training Stage:}

At this stage, the federation all staff and its various committees will be trained on how to implement the devised plan and work out solutions and alternatives for the expected problems ahead.

\section{Fourth- Implementation Stage:}

It aims to implement the plan as implementation is carried out at the top management level. The process starts with selecting the quality management members according to certain standards and then selecting representatives of public and private universities and colleges which are the federation members.

\section{Fifth- Follow-up and Assessment Stage:}

It is keen on the program continuity in achieving quality for the purpose of improvement through the program continued assessment to identify the positive and negative aspects, work out to expand the participation base, introduce further objective training programs, clarify the good results achieved through the program and to the distinguished individuals. Thus, the researchers have answered the third question: What is the suggested conceptualization of the administrative in the light of The essential elements of total quality?

\section{Conclusions:}

The researchers have concluded the following:

1. The SUSF objectives are characterized by clarity.

2. The plans made by the federation are consistent with the general goals of sports welfare movement in Saudi Arabia

3. The SUSF has rules, regulations, and systems organizing administrative work.

4. The SUSF has an accredited organizational structure.

5. There is lack of implementing the principles total quality assurance from beneficiaries' views.

6. There is a weakness supervision of SUSF monitoring role 
7. Resources availability to SUSF for implementing total quality assurance

8. A lack of preparing and training of human cadres.

\section{Recommendations:}

In the light of the research aim, the limitations of the research population and the selected sample and the concluded findings, the researchers provide the following recommendations:

1. Setting clear and defined objectives for all member universities and colleges that take part in the SUSF activities.

2. Providing subjective assessment tools to verify the achievement of the essential elements of total quality at the federation.

3. Developing long-term plans that aim to develop the administrative work system at the federation.

4. Attention should be paid to the training of the federation's staff and coordinators, who are affiliated to its member universities and colleges, on the total quality system according to their needs, abilities and aspirations.

5. Attention should be paid to the customers' and beneficiaries' satisfaction with the services provided by the federation.

6. The federation's staff and coordinators, who are affiliated to its member universities and colleges, should participate in setting the objectives, plans and decision taking.

7. It is necessary to implement the suggested conceptualization that may increase administrative work efficiency at the federation in the light of the essential elements of total quality which the research findings have concluded.

\section{References}

\section{First- Arabic references:}

1. Saudi Universities Sports Federation: "Organizational Chart of the Saudi Universities Sports Federation ", Kingdom of Saudi Arabia.

2. Omnya Mahmoud Hussein, Iman Abdel-Wahab, \& Hallah Mohamed Labib: Assessment of the Open Learning System, from the Total Quality Perspective with Application to Cairo University, No. 2, April, Faculty of Commerce, Ain Shams University, 1998.

3. Bahgt Attiya Bahgt: Total Quality Management as an Approach to Developing Egyptian Sports clubs in the Light of Contemporary Global Changes, Ph.D. Dissertation, Faculty of Physical Education for Males, Helwan University, Cairo, 2002.

4. Gamal Tahir Abu Al-Fetouh: Total Quality Management: An Approach to Improving Product Quality in the Textile and Spinning Industry in the Arab Republic of Egypt, Ph.D. Dissertation, Faculty of Commerce, Zagazig University, 1996.

5. Gamal Mohamed Ali Youssif: "The Motivation Pattern of Sports Specialists at Egyptian Universities," Assiut Journal of Physical Education Sciences and Arts, Assuit University, 2003.

6. Gamal Mohamed Ali Youssif: Administrative Development at the Sports and Public Administration, Book Publishing Center, Cairo, 2008.

7. Gamal Mohamed Ali Youssif: On Sports Administration, $2^{\text {nd }}$ edition, Dar El-Fikr Al-Arabi, Cairo, 2009.

8. Hassan Ahmed El-Shafae, "Advertising in Sports and Physical Education, Al-Wafaa Printing and Publishing House, Alexandria, 2003.

9. Hamed Hussein Ahmed and Abdallah Farghali Ahmed: "A Suggested conceptualizationualization for the Implementation of Total Quality Management at the Egyptian Athletic Federation," Published Paper, Scientific Conference of the Faculties of Education, Faculty of Education, Mansoura University, May, 2004.

10. Ramzi Ahmed Mostafa and Kamal Mahmoud Marzouq: "The Effective Role of Management in University Development," Scientific Symposium on the Future Challenges Facing University Education, Tripoli, Libya, 2005.

11. Suad Basyouni, "Total Quality Management: An Approach to Developing University 
Education," Part3, No. 20, Journal of the Faculty of Education and Psychology, Ain Shams University, 1996.

12. Said Yassin Amer: Change Strategies, Waleed Service Centre for Consultation and Managerial Development, Cairo, 1994.

13. Shaza Awzat Hourna: "The Impact of Using Total Quality on the Public Sector with Application to the Ministry of Education and Youths in the United Arab Emirates", Ph.D. Dissertation, National Institute for Top Management, Sadat's Academy for Management Sciences, Cairo, 2001.

14. Lilay Zahran: Scientific and Technical Principles of Curriculum Construction in the Physical Education, Zahran Publishing and Distribution House, Cairo, 2003.

15. Mohamed Raafat Mahmoud: "University Performance Evaluation: A Leading experience in Assuit University," Journal of Egyptian Universities, No. 25, Assuit University, July, 2003.

16. Mohamed Abbas Mohamed: "Total Quality Management and its Applicability at South Valley University in the Light of its Organizational Culture", Ph.D. Dissertation, Faculty of Education, Assuit University, 2003.

17. Mamdouh Mahmoud Mohamed: "Evaluation of Sports Activity at South Valley University in the Light of the essential elements of Total quality", M.A. Thesis, Faculty of Education, Assuit University, 2007.

18. Mona Abdel Monem: "A Proposed Model of Total Quality Management at the Egyptian Table Tennis Federation", Ph.D. Dissertation, Faculty of Physical Education, Assuit University, 2005.

19. Nagi Ismael Hamed: "Planning at the Olympic Sports Federations in the Light of the Egyptian Sports Strategy", Ph.D. Dissertation, Faculty of Physical Education for Males, Helwan University, 1999.

20. Nazmi Nasrallah: The Beginning of Road to the Development of the Administrative Perspective, Arab Co. for Publishing and Distribution, Cairo, 1995.

\section{Second- Foreign References:}

21. Abraham Ramirez. H. Doris: Sources of Influence on Faculty Members Receptivity to Continue Quality improvement Initiatives (Total Quality Management), Ph.D. The Pennsylvania State University, 1997.

22. Erhan, Mergen \&Etal: Quality Management Applied to Higher Education, Total Quality Management, Vol. 11, No. 3, May, 2000.

23. Gitlow Oppenheim: Quality Management: Bookss and Methods for Improvement, $2^{\text {nd }}$ edition, Irowa, Inc, 1994.

24. Lagan Patrick William: A Study of the Use of Teams in the Quality University Servieesat the University of (IOWA). Ph.D.; The university of IOWA, 1998.

25. Mcdaniel Dayna Marlene: Effective Total Quality Management Implementation by Capital City Government (Local Government) Dpa; The University of Albama,1997.

26. Oebbecke Markus: Toward a framework of Total Quality Management (TQM) in Professional Sport Team Organizations: Identification and Validation of TQM Constructs, EDD; Tenple University, 1998. 